\title{
Multifocal choroiditis following simultaneous hepatitis A, typhoid, and yellow fever vaccination
}

This article was published in the following Dove Press journal:

Clinical Ophthalmology

16 February 2013

Number of times this article has been viewed

\author{
Sarah Escott \\ Ahmad B Tarabishy \\ Frederick H Davidorf \\ Havener Eye Institute, The Ohio State \\ University, Columbus, $\mathrm{OH}$, USA
}

Correspondence: Frederick H Davidorf 915 Olentangy River Rd, Columbus, $\mathrm{OH} 43212$, USA

$\mathrm{Tel}+\mathrm{I} 6146522600$

Fax + I 6/4 2933555

Email Frederick.davidorf@osumc.edu
Abstract: The paper describes the first reported case of multifocal choroiditis following simultaneous hepatitis-A, typhoid, and yellow fever vaccinations. A 33-year-old male developed sudden onset of flashing lights and floaters in his right eye 3 weeks following hepatitis A, typhoid, and yellow fever vaccinations. Fundus examination and angiography confirmed the presence of multiple peripheral chorioretinal lesions. These lesions demonstrated characteristic morphologic changes over a period of 8 weeks which were consistent with a diagnosis of self-resolving multifocal choroiditis. Vaccine-induced intraocular inflammation has been described infrequently. We demonstrate the first case of self-resolving multifocal choroiditis following simultaneous administration of hepatitis A, yellow fever, and typhoid immunizations.

Keywords: multifocal choroiditis, vaccination, hepatitis A, typhoid, yellow fever

\section{Case report}

A previously healthy 33-year-old male was referred to our retina service for sudden onset of intermittent floaters and flashing lights in his right eye which developed 3 weeks following inactivated hepatitis A, yellow fever, and typhoid vaccinations. These vaccines were given prophylactically in preparation for a 2-week trip to Panama at the Ohio State University Wexner Medical Center Travel and Immunization Clinic. The patient had previously received one dose of the hepatitis A vaccine 12 years prior (he did not complete the series) and had never before been exposed to typhoid or yellow fever immunizations.

On examination, visual acuity was $20 / 20$ in both eyes. Pupil responses, visual fields to confrontation, and intraocular pressures $(14 \mathrm{mmHg})$ were normal bilaterally. Slit lamp examination revealed $1+$ anterior vitreous inflammation bilaterally. Fundus examination of the right eye revealed a few scattered peripheral nonpigmented chorioretinal lesions. The macula and optic nerve appeared normal, and the left fundus was unremarkable. Fluorescein angiography of the right eye demonstrated scattered peripheral hyperfluorescent lesions correlating with those seen in the fundus, and there was no evidence of disc leakage (Figure 1). A comprehensive review of systems was negative for fever, rash, oral ulcers, arthralgias, headache, or vertigo. There was no history of autoimmune disease or recent viral illness. There was no family history of autoimmune disease. The patient was diagnosed as having acute multifocal choroiditis and observed. After 2 weeks, the patient continued to describe occasional floaters. His ocular examination revealed continued low grade anterior vitreous inflammation and the peripheral retinal lesions began to demonstrate early hyperpigmentation (Figure 2). Because of the nonprogressive examination findings and given the excellent visual 


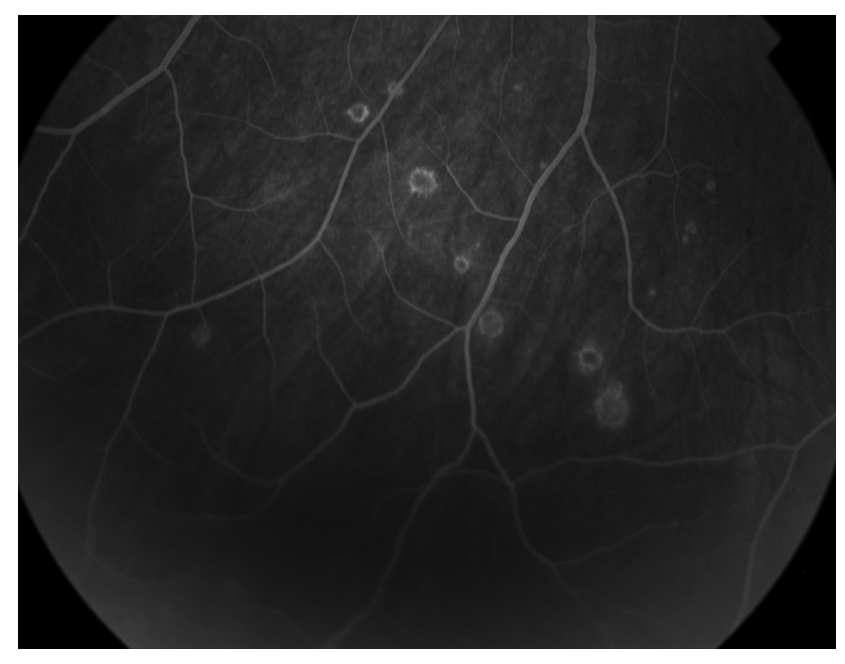

Figure I Late frame fluorescein angiographic photograph of the right eye demonstrating well demarcated hyperfluorescent lesions.

acuity, it was decided to continue close observation. At 8 weeks, the patient's symptoms had resolved, the vitreous was clear of cellular inflammation, and the fundus revealed punched out areas of retinal pigment epithelium atrophy.

\section{Discussion}

Vaccines potentiate both humoral and cellular immune responses by exposing lymphocytes to pathogen-specific antigens which triggers an inflammatory $\mathrm{T}$ cell-mediated reaction and initiates the steps of adaptive immunity and development of cellular memory. Autoimmune phenomena have been infrequently observed following vaccination, and possible mechanisms proposed to explain some of these occurrences include the roles of excessive lymphocyte activation, cytokine expression, and molecular mimicry. ${ }^{1}$

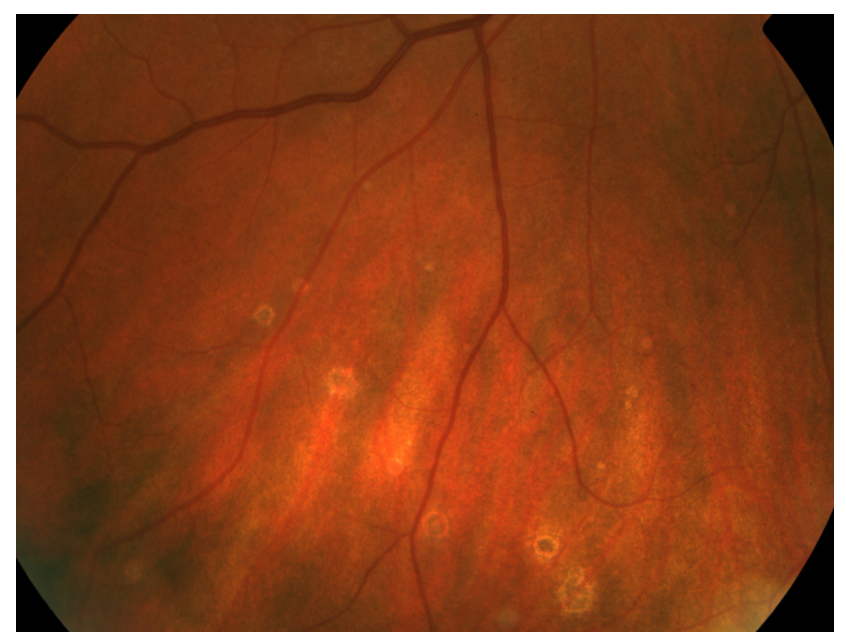

Figure 2 Color fundus photograph of the right eye demonstrating well circumscribed chorioretinal lesions with hyperpigmentation.
Cross-reactivity of an activated immune response against uveal antigens may occur when peptide fragments presented to $\mathrm{T}$ cells show close conformational resemblance to uveal self-peptides. Melanin-associated molecules present in choroid have been shown experimentally to be capable of inducing ocular inflammation. ${ }^{2}$

Another possible method of immune system activation following vaccination relates to the use of vaccine adjuvants. Adjuvants are routinely combined with vaccines to potentiate their immunogenic activity and these have been used in animal models to create uveitis. ${ }^{2}$ Aluminum-containing adjuvants are used widely in vaccine formulations licensed for use in the US, including hepatitis A. Crucial to the adjuvant activity of aluminum is the influx of inflammatory factors, including dendritic cells, to the site of injection. These cells can recognize and process foreign antigens, as well as provide the costimulatory molecules necessary for activating plasma cell production of target antibodies. ${ }^{3}$ Rarely, erythema, subcutaneous nodules, contact hypersensitivity, and granulomatous inflammation have been observed with the use of aluminum adjuvants. ${ }^{4}$ The currently used preparation of typhoid and yellow fever vaccines are free of adjuvants.

There are a few case reports in the literature describing posterior uveitis syndromes occurring shortly after vaccination. Specifically, multiple evanescent white dot syndrome was reported 10 days following simultaneous hepatitis $\mathrm{A}$ and yellow fever vaccines, and acute posterior multifocal placoid pigment epitheliopathy was described in association with hepatitis $B$ and varicella vaccinations..$^{5-7}$ A review of 32 cases of uveitis following hepatitis $B$ vaccination included a few reports of positive rechallenge response in patients who developed recurrent uveitis following separate doses of the hepatitis B vaccine. ${ }^{8}$ Most of the reported cases of uveitis demonstrated self-resolution, although recently a case of ampiginous choroiditis was described following human papilloma virus vaccination which required treatment with oral prednisone and resulted in macular scarring. ${ }^{9}$

Multifocal choroiditis is an inflammatory disease characterized by multiple, small, yellow fundus lesions, and vitreous inflammation. Presenting symptoms include blurry vision, floaters, and photopsias. Although the etiology of multifocal choroiditis remains unknown, there have been suggestions of autoimmune and viral associations. The primary location of pathology involves the retinal pigment epithelium. The choriocapillaris and choroid are richly invested with certain potential antigen-presenting cells and the retinal pigment epithelium can be induced to express major histocompatibility complex Class II molecules, suggesting 
it may be able to interact with $\mathrm{T}$ lymphocytes. There is experimental evidence that high densities of $\mathrm{T}$ lymphocytes, B lymphocytes, and macrophages can infiltrate the choroid and stimulate synthesis of cytokines capable of altering the subsequent immune response. ${ }^{10}$ During the late stage of the disease, the spots adopt a rim of hyperpigmentation and often assume the classic punched-out appearance of retinal pigment epithelium atrophy with bands of subretinal fibrosis at their margins. To our knowledge, this is the first reported case of multifocal choroiditis following vaccination.

Although this case does not prove causation and the relationship remains presumptive, it does suggest that some vaccinations can act as a trigger for immunologic initiation that could subsequently lead to the development of noninfectious uveitis.

\section{Disclosure}

The authors report no conflicts of interest in this work.

\section{References}

1. Jampol LM, Becker KG. White spot syndromes of the retina: a hypothesis based on the common genetic hypothesis of autoimmune/inflammatory disease. Am J Ophthalmol. 2005;135:376-379.

2. Borekhuyse RM, Kuhlmann ED, Winkens HJ. Experimental autoimmune anterior uveitis (EAAU). Induction by immunization with purified uveal and skin melanins. Exp Eye Res. 1993;56:575-583.
3. Kool M, Fierens K, Lambrecht BN. Alum adjuvant: some of the tricks of the oldest adjuvant. J Med Microbiol. 2012;61:927-934.

4. Gupta RK. Aluminum compounds as vaccine adjuvants. Adv Drug Deliv Rev. 1998;32:155-172.

5. Stangos A, Zaninetti M, Petropoulos I, Baglivo E, Pournaras C. Multiple evanescent white dot syndrome following simultaneous hepatitis A and yellow fever vaccination. Ocular Immunol Inflamm. 2006;14: 301-304.

6. Fine L, Fine A, Cunningham ET. Multiple evanescent white dot syndrome following hepatitis A vaccination. Arch Ophthalmol. 2001;119:1856-1857.

7. Fine HF, Kim E, Flynn TE, Gomes NL, Chang S. Acute posterior multifocal placoid pigment epitheliopathy following varicella vaccination. Br J Ophthalmol. 2010;94:282-283.

8. Fraunfelder FW, Suhler EB, Fraunfelder FT. Hepatitis B vaccine and uveitis: an emerging hypothesis suggested by review of 32 case reports. Cutan Ocul Toxicol. 2010;29:26-29.

9. Khalifa YM, Monahan PM, Acharya NR. Ampiginous choroiditis following quadrivalent human papilloma virus vaccination. $\mathrm{Br} \mathrm{J}$ Ophthalmol. 2010;49:137-139.

10. Streilein JW, Ma N, Ng TF, Zamiri P. Immunobiology and privilege of neuronal retina and pigment epithelium transplants. Vision Res. 2002;42: $487-495$.
Clinical Ophthalmology

\section{Publish your work in this journal}

Clinical Ophthalmology is an international, peer-reviewed journal covering all subspecialties within ophthalmology. Key topics include: Optometry; Visual science; Pharmacology and drug therapy in eye diseases; Basic Sciences; Primary and Secondary eye care; Patien Safety and Quality of Care Improvements. This journal is indexed on

Submit your manuscript here: http://www.dovepress.com/clinical-ophthalmology-journal

\section{Dovepress}

PubMed Central and CAS, and is the official journal of The Society of Clinical Ophthalmology (SCO). The manuscript management system is completely online and includes a very quick and fair peer-review system, which is all easy to use. Visit http://www.dovepress.com/ testimonials.php to read real quotes from published authors. 